\title{
THE LONGEVITY OF BASEBALL HALL OF FAMERS COMPARED TO OTHER PLAYERS
}

\author{
ERNEST L. ABEL \\ Departments of Obstetrics/Gynecology and Psychology, \\ Wayne State University, Detroit, Michigan, USA
}

\section{MICHAEL L. KRUGER}

Department of Obstetrics/Gynecology, Wayne State University, Detroit, Michigan, USA

\begin{abstract}
The authors compared the longevity of all baseball players alive at the time of their induction into the Baseball Hall of Fame with age-matched controls who were likewise alive at the time of the Hall of Famer's induction, and also matched them for career length, player position, and body-mass index, to assess if fame in sports is associated with increased longevity. Median post-induction survival for Hall of Famers was 5 years shorter than for noninducted players (18 vs. 23 years, respectively). In a second analysis, significantly more Hall of Famers died of cardiovascular or stroke causes than other players for whom cause of death was known. Baseball fame may have a hitherto unrecognized price.
\end{abstract}

Studies of longevity among elite athletes compared to the general public have yielded conflicting results with some studies reporting lower than expected mortality (Karvoneme, Klemola, Virkajarvi et al., 1984; Schnohr, 1971; VanSaase, Noteboom, \& Vanderbroucke, 1990); whereas others have not found significant differences (Beaglehole \& Stewart, 1983; Waterbor, Cole, Delzeli, \& Andjelkovitz, 1988). Sarna et al. (1993) found evidence for both outcomes depending on whether an athlete was engaged in aerobic (e.g., long distance running or soccer) or power sports (e.g., wrestling). Those excelling in aerobic sports had significantly increased longevities although those excelling in power sports did not.

In contrast to studies of whether participation in sports affects longevity, there are relatively few studies within specific sports of

Received 20 December 2004; accepted 20 June 2005.

Address correspondence to Ernest L. Abel, Ph.D., C.S. Mott Center for Human Growth and Development, 275 East Hancock, Detroit, MI 48201. E-mail: eabel@wayne.edu 
the relation between longevity and awarded achievement (Sarna et al., 1993). Professional baseball provides an excellent database from which to examine this question because it has a history of detailed statistics (James, 1995). Other studies have used this database to compare longevity of major league players and the general public (Metropolitan Life Insurance, 1975; Waterbor et al., 1988; Abel \& Kruger, 2004), but it has not hitherto been used to evaluate the role of awarded achievement within the sport on longevity.

In the present study we used the professional baseball player database to address the question of whether awarded achievement affects longevity. Our study was prompted by another study using a different data set, which found that Academy Award winners lived about 4 years longer than controls (Redelmeir \& Singh, 2001). Winning more than one Academy Award increased survival to 6.0 years longer compared with performers with multiple film performances but no such award. In our study, we tested the hypothesis that professional major league baseball players inducted into the Baseball Hall of Fame, the highest accolade of achievement in the sport (James, 1995) have longer longevities compared to players of the same age who are not inducted. Given that induction could only have such an effect if the inductee or nominee were alive at the time of recognition, we compared players who were inducted while alive with other players of the same age who were alive at the time of the Hall of Famers' induction.

\section{Methods and Materials}

We compared all Major League baseball players listed in the Baseball Archive v.5 database (Lahman, 2002). Players were categorized as either: (a) inducted into the "Hall of Fame" while alive (cases) or (b) all age-matched players who were alive at the time of induction when induction occurred for their case-matched cohort. Only players were included in our analysis (executives, announcers, umpires were not included; managers were included who had also been players).

Our outcome variable was longevity, as defined by postinduction survival time. Cox Proportional-hazards Survival analysis was used to determine whether differences in survival between the groups were significant, controlling for career length, player position, and body mass index (BMI). All statistical tests 
were two-tailed and probabilities of $p<.05$ were considered statistically significant.

A secondary analysis was then conducted comparing cause of death for all Hall-of-Famers compared with other players, matched for year of birth and number of years played ( \pm 2 years). Cause of death was obtained from Lee (2003) and The Deadball Era (www.thedeadballera.com). Initially categories included the 10 leading causes of death (NCHS, 2003) but because most of the categories had fewer than five cases per cell, causes of death were recategorized as "cardiovascular and stroke," "cancer," and "other." Cases and controls were then compared using the chi-squared statistic.

\section{Results}

The total data set contained 3,573 Hall-of-Famers and their agematched controls. One hundred and forty-three (143) players in the Hall of Fame had been inducted into the Baseball Hall of Fame while still alive as of 2002. These were age-matched with 3,430 players. The mean age of the Hall of Famers at time of induction was 57.5 years $(S D \pm 12.4)$. A total of 1,695 of these players had died by the end of 2002 .

Hall-of-Famers died significantly earlier than their controls. The median length of post-induction survival for the Hall of Famers was 18 years $(95 \% \quad \mathrm{CI}=15.0-21.0)$ versus 23 years $(\mathrm{CI}=22.1-23.9)$ for matched controls (Odds ratio $[\mathrm{OR}]=1.37$; $95 \% \mathrm{CI}=1.08-1.73)$. A higher percentage $(64 \%, n=92)$ of the Hall of Famers were also dead compared with controls $(47 \%$, $n=1,603)$ who were the same age at the time of the Hall of Famer's induction $\left(\chi^{2}=17.1, d f=1, p<.001\right.$. Player position and career length did not significantly affect post-induction survival. BMI, however, did affect survival significantly. Hall-of-Famer's had a mean $( \pm S D)$ BMI of $25.2 \pm 1.8$ versus $24.7 \pm 1.5$ for controls. This difference was statistically significant $\left(t_{n=3,114}=3.6, p<.001\right.$.)

Cause of death was available for 97 players in the Hall of Fame and 72 controls. Group differences were statistically significant $\left(\chi^{2}=13.1, d f=2, p<.001\right)$. Hall of Famers were twice as likely to have died from cardiovascular or stroke causes as controls. (53\% [ $n=51]$ vs. $25 \%[n=18]$, respectively). Prevalence of cancer was lower in Hall of Famers $(23 \%$ [ $n=22]$ vs. $33 \%[n=24])$ but this difference was not statistically significant. 


\section{Discussion}

Players inducted into the Baseball Hall of Fame are chosen by about 500 members of the Baseball Writers Association of America and a select group of about 20 veteran players, on the basis of player excellence over a number of years (James, 1995). To be selected, a player must have had a career lasting at least 10 seasons. He becomes eligible for nomination five years after retirement. To be inducted into the Hall of Fame, he must receive $75 \%$ of the ballots. Players can be nominated for no more than 15 years, after which they become ineligible (James, 1995). Whereas length of career and performance are essential for nomination, neither are sine qua nons for induction. In many cases, players with longer careers or better performance statistics than inductees have not been inducted in the Hall of Fame (James, 1995). In this study we compared life expectancies of players inducted into the Hall of Fame while they were still alive with players of the same age who were not inducted, but who were also alive at the time of the Hall of Famers' induction, controlling for career length, player position, and BMI.

Our finding that players inducted into the Baseball Hall of Fame while still alive had shorter longevities compared with age-matched players who were not inducted does not support the role of celebrity on longevity as suggested in a study of Academy Award Winners (Redelmeir \& Singh, 2001). Whereas the increased income associated with celebrity may extend longevity because it confers better access to health care, special privileges, and ability to reduce stress (Detsky \& Redelmeir, 1998; Redelmeir \& Singh, 2001), there was no way to test the role of any of these collateral benefits in the study of Academy Award Winners or in the present study, or assess risk factors such as smoking and alcohol consumption. However, we did note that players in the Hall of Fame had a higher BMI than controls (but both BMIs were in the average range for body mass) and were much more likely to die of cardiovascular/stroke-related causes. Some possibilities are that Hall-of-Famers have some condition prior to induction that affects this longevity (e.g., heavier body weights) become heavier users of alcohol after their induction, or engage in other risk factors after induction that shorten their longevity. 


\section{References}

Abel, E. \& Kruger, M. (2004). Left-handed major-league baseball players and longevity re-examined. Perceptual and Motor Skills, 99, 990-992.

Beaglehole, R. \& Stewart, A. (1983). The longevity of international rugby players. New Zealand Medical Journal, 96, 513-514.

Detsky, A. S. \& Redelmeir, D. A. (1998). Measuring health outcomes-putting gains into perspective. New England Journal of Medicine, 339, 402-404.

James, B. (1995). What ever happened to the hall of fame? New York: Fireside Books.

Karvoneme, M.J., Klemola, H., Virkajarvi, I., \& Kekkonen, A. (1984). Longevity of endurance skiers. Medicine and Science in Sports, 6, 49-51.

Lahman, S. (2002). The Baseball Archive v.5.0. Available at http//www.baseball.com.

Lee, B. (2003). The baseball necrology: The post-baseball lives and deaths of over 7,600 major league players and others. Jefferson, NC: McFarland \& Co.

Metropolitan Life Insurance Company. (1975). Longevity of major league baseball players. Statistical Bulletin, 56.

Redelmeir, D. A. \& Singh, S. (2001). Survival in academy award-winning actors and actresses. Annals of Internal Medicine, 134, 955-962.

Sarna, S., Sahi, T., Koskenvuo, M., \& Kaprio, J. (1993). Increased life expectancy of world class male athletes. Medicine and Science in Sports and Exercise, 25, 491-495.

Schnohr, P. (1971). Longevity and causes of death in male athletic champions. Lancet, 2, 1364-1365.

Van Saase, J. L. C. M., Noteboom, M. P., \& Vanderbroucke, J. P. (1990). Longevity of men capable of vigorous physical activity exercise: A 32 year follow-up of 2259 participants in the Dutch eleven cities ice skating tour. British Medical Journal, 301, 1409-1411.

Waterbor, J., Cole, P., Delzeli, E., \& Andjelkovitz, D. (1988). The mortality experience of major league baseball players. New England Journal of Medicine, $318,1278-1280$. 